\title{
Governing the future and the search for spatial justice: Wales' Well-being of Future Generations Act
}

\author{
RHYS JONES
}

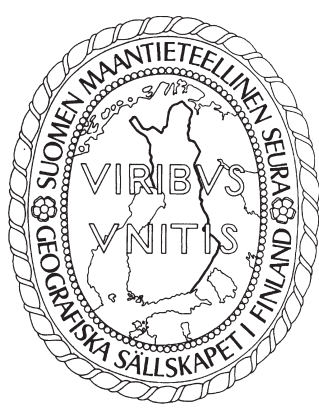

Jones, R. (2019) Governing the future and the search for spatial justice: Wales' Well-being of Future Generations Act. Fennia 197(1) 8-24. https://doi.org/10.11143/fennia.77781

$\mathbf{y}$ Recent contributions in Geography and beyond have examined historical and more contemporary efforts to govern the future. Work in this area has highlighted some important conceptual considerations by drawing attention to the way in which states, regions and other organisations view the future as an object of governance for a variety of reasons: as something that constitutes a threat that needs to be managed; as something that can be predicted, thus leading to an improvement in governance; as something that allows a more hopeful and just society, economy and environment to be expressed (and achieved). In this paper, I use this context as a way of making an argument for the need to: 1) consider more explicitly the many geographies associated with governing the future; and 2) explore how these geographies might impact on the definition and promotion of spatial justice. I illustrate these arguments through an empirical discussion of the development and implementation of Wales' Well-being of Future Generations Act, an Act that seeks to create a better and more just Wales by the year 2050. I conclude by exhorting geographers to take the lead in exploring the impact that geographical themes might have on states' and regions' attempts to achieve spatial justice in the present and the future.

Keywords: futures, governance, spatial justice, Well-being of Future Generations Act, Wales

Rhys Jones, Aberystwyth University, Aberystwyth, SY23 3DB, United Kingdom. E-mail: raj@aber.ac.uk

\section{Introduction}

Recent contributions in Geography and beyond (e.g. Anderson 2010; Andersson 2012) have reflected on the historical and more contemporary efforts to govern the future. ${ }^{1}$ Work in this area has highlighted some important conceptual considerations by drawing attention to the way in which states, regions and other organisations view the future as an object of governance for a variety of reasons: as something that constitutes a threat that needs to be managed; as something that can be predicted, thus leading to an improvement in governance; as something that allows a more hopeful and just society, economy and environment to be expressed (and achieved). Studies of the governance of the future has also been characterised by considerable empirical breadth. Detailed work has been conducted, for instance, on the historical geographies of the study of the future and its links to the Cold War (Andersson \& Keizer 2014), along with more contemporary concerns surrounding future governance in the context of terrorism and security (Massumi 2007), the radicalisation of youth a Creative Commons Attribution 4.0 International License. 
(Saunders \& Jenkins 2012), infectious diseases and pandemics (Hinchcliffe \& Bingham 2008) and ecological disaster (Hulme 2008).

This research is to be commended for its detailed and sophisticated conceptualisation and empirical examination of the governance of the future. My aims in this article, however, are to foreground two themes that have, arguably, not been examined in sufficient detail to date. First, I suggest that there needs to be a more explicit examination of the significant geographies that characterise the governance of the future; geographies that have only been addressed in implicit ways in pre-existing studies of the governance of the future. When I refer to significant geographies, I mean that there is a need, for instance, to highlight how the governance of the future occurs differently in different places and emerges as a result of a movement of people, things and ideas from one location to another (cf. Baker \& McGuirk 2017). There is a need, likewise, to examine how the governance of the future becomes embedded in various ways in particular states, nations and regions (Jones \& Ross 2016). Equally, we should develop a more explicit awareness of how the governance of the future is played out across a series of connected geographical scales, ranging from the global to the embodied and everything else in between (Diprose et al. 2008). Second, I suggest that a focus on these geographies can help us to envision and promote a more hopeful and just version of the future. I maintain that there are, potentially, important connections here between literatures on the governance of the future and recent debates concerning the idea of spatial justice. While the notion of spatial justice has varied meanings (Jones et al. 2019), it is, in essence, concerned with understanding the interconnections between space and justice. Dabinett $(2011,2391)$ has argued that we should avoid seeing space as merely being a container for justice. Instead, we need to consider how space can influence forms of justice and injustice in various. It is in this context that we need to attend to the impact that geographies of different kinds might have on the governance of more equal and just futures.

The remaining sections of this paper are arranged as follows. In the following section, I discuss in more detail the various ways in which the governance of the future has been approached to date. I also elaborate on the value of adopting a more explicitly geographical take on the governance of the future, particularly as a way of furthering more spatially just futures. In the subsequent section, I provide some background detail on the case study I have chosen for this article, namely Wales' Wellbeing of Future Generations Act (2015) (hereafter the Well-being Act). I contend that it is an Act that has the notion of justice - understood in relation to the concept of well-being - at its heart. It is also an Act that seeks to govern the future of Wales in explicit ways. The passing of this Act places an onus on all public bodies in Wales to consider the impact that their present policies and procedures might have on future generations and, moreover, to ensure that their actions in the present will help to maximise the well-being of Wales' citizens of the future, with the year 2050 acting as a significant end goal (Jones \& Ross 2016). I also discuss in this section the methods and fieldwork that underpin the arguments I make in the article. In the penultimate section, I delve into more empirical detail by examining the way in which the Act has sought to govern the future across and between three distinct, yet interconnected scales: the scale of Wales as a region, devolved state and nation; the local scale within Wales, a scale at which much of the Act has been operationalised; the scale of individual and embodied civil servants in Wales, who are responsible for making the Act work in practice. Brief conclusions appear in the final section, in which I reflect more broadly on the significance of geography and scale for the governance of more hopeful futures.

\section{Governing the future}

As noted in the introduction, there has been a growth in recent years in academic interest in the various ways in which the future has been, and continues to be, an object of governance for states, regions, cities and other organisations. A number of important themes have been highlighted by academics in relation to this object of governance.

First, many academics have commented on the way in which the future has been viewed as a threat or as a risk that needs to be managed and governed (Beck 1992). Work by Andersson (2012; Andersson \& Keizer 2014) has examined what could be termed the historical geographies of these attempts to govern risky futures. Andersson and Keizer (2014), for instance, trace the beginnings of attempts to 
govern these risky futures to the Cold War. It was during this period, for instance, that the science of Futurology first emerged, in which various techniques (e.g. Delphi method) and technologies (e.g. emerging forms of computer simulation) were developed by key actors, such as the RAND organization, in order to manage the risks associated with the Cold War; most notably the risks of nuclear annihilation (ibid., 425). It is in this context too that the familiar Rostow model of progress and economic development emerged as a more positive account of the futures that would characterize western states; a model that was defined in opposition to the alternative Marxist models of progress and development fashioned in the Soviet Union and its satellite states (Andersson 2012).

More recent attempts to govern risky futures have been studied in Geography by Anderson (2010). He has noted how "preemption, precaution and preparedness" have become watchwords in recent years, whether in relation to the need to reduce the threat of: terrorism, especially post 9/11 (Massumi 2007); infectious diseases and pandemics, such as SARS (Hinchcliffe \& Bingham 2008); ecological disaster, especially one associated with climate change (Hulme 2008). What unites these attempts to govern risky futures is the way in which the future becomes a space of governmental calculation but also something that extends beyond scientific calculation into the realms of imagination (Anderson 2010, 785): a shift from what will happen to what might happen. And of course, the emphasis on the riskiness of the future - and of the need to govern this effectively - also raises significant questions about the role of affect in the governance of the future. The apocalyptic fears associated with certain forms of pandemic and climate change, in particular, highlight how a consideration of affect needs to take center stage in any engagement with the governance of risky futures (Boykoff 2008). This is a theme to which I return below, albeit in more positive and hopeful ways.

A second area of enquiry has centered on attempts to think about the future as something that can be predicted, for the purpose of improving societies, economies, as well as ways of governing them. As part of this attempt to think about the future as a time and space to be calculated (Anderson 2010, 784), emphasis has been placed on developing models, projections, scenarios and so on to try to predict the future; as a more neutral aid to governance. While such developments have taken place in many different states, it has, arguably been something that has appealed more in some states than others. Centralised states, in particular, seem to have placed greater emphasis on predicting and planning for the future. Andersson $(2012,1421)$, for instance, discusses the role of the prognostik movement in the USSR and its efforts to use "predictive social and economic indicators to monitor progress and change". Similarly, the centralising tendencies of the French state led to technocratic models of prediction being incorporated into the French Plan (Anderson \& Keizer 2014, 108).

A number of interesting issues arise in relation to this attempt to predict the future. Some have criticised the tendency of such approaches to fall foul of 'path dependency', teleology or what has been termed "chronological imperialism" (Galtung in Andersson 2006, 281); in other words, a tendency to view the future as something that is pre-ordained by the past or present in the particular geographical setting in question or, even more problematically, by the past and present of other places, regions or states (as in Rostow's model of development or the demographic transition model, where one state is said to follow the path set by other, more 'advanced' states). I shall return to these criticisms below but suffice to say that such models and predictions tend for foreclose any sense of openness or potential in the future. Another key issue in relation to predicting the future - and one that perhaps contradicts the first point - has revolved around the inherent uncertainty of doing so. For instance, Andersson and Keizer $(2014,116)$ note that the WRR, a body responsible for governing the future of the Netherlands, "came to the conclusion [in the 1970s] that prediction was a very difficult activity".

The emphasis on prediction with the governance of the future has also possessed some important disciplinary and methodological consequences. The study of the future has always been interdisciplinary but there is some evidence to suggest that early forms of Futurology during the 1950s and 1960 s tended to emphasize the significance of the hard sciences and Economics. These early forms of prediction were heavily dependent on statistics and computer modelling, and were augmented from the 1970s onwards by more open and plural explorations of possible futures. This shift to a broader Futures Studies (the emphasis on Futures in the plural is significant) was associated with a greater emphasis on the conceptual and methodological expertise of disciplines in the Social Sciences and 
Arts. An important example of this development was the formation of the Swedish Futures Studies Group during the early 1970s. It included a professor of Psychology, Geography (Torsten Hägerstrand), Mathematics and Planning Theory, and History (ibid.). Futures Studies, in this way, rejected Futurology "as law-driven science", maintaining that "the future could not be addressed with established tools of science such as facticity and empirical observation" (Andersson 2012, 1426). New and alternative methods were developed in order to imagine alternative futures, including scenario building (including the use of pictures, case studies, narrative accounts and other kinds of more qualitative data). In all this, we witness an attempt to move away from data and methods that foreclose the future to data and methods that open it up to discussion and debate. And, in more philosophical terms, this development reflects an effort to question hegemonic accounts of a singular and predetermined future by highlighting the multiple versions of the future that could be problematized and imagined (cf. Rose 1999; Dikeç 2007).

The above discussion of the emergence of Futures Studies alludes to a third approach to the governance of the future; namely the way in which the governance of the future has been viewed as something that can express hope and enable a search for social (and spatial) justice. A focus on the potential of the future as a time and space of hope derives in large measure from a dissatisfaction with the closed and limiting kinds of future envisaged within predictive models of the future. This more open account of the future also derives from a belief that the present is complex and, as such, makes the future open and difficult to determine (Anderson 2010). The future, when viewed in this way, shifts from being: "as an is: an object of science of which certain predetermined traces could be found...[to]...the future as becoming: an object of the human imagination, creativity and will" (Andersson 2012, 1413).

There are clear parallels here with work in Geography and beyond on the notion of hope and utopia. Harvey (2000), in particular, has attempted to map out an academic and political agenda that can allow us to envisage more just and equal alternatives to the political-economic and embodied consequences of living and working in late capitalism. His represents a particular interpretation of what a more just future might look like, of course. But a key attribute of Futures Studies - as opposed to Futurology - is its emphasis on the need to envisage a range of alternative futures. As part of this, the future becomes a "surprise" (Anderson 2010, 783) and something, borrowing from Mouffe (2013), which is enriched by deliberation, debate and agonism. And if a fear of the uncertainty of the future, as discussed earlier, displays the affective significance of governing the future, so does a focus on the future as a space and time of hope. As Saunders and Jenkins $(2012,494)$ note, '"envision' is a very hopeful word and 'to envision' is an act full of promise. It carries with it very positive...connotations that imply optimism, enthusiasm and confidence".

The above discussion illustrates the richness of the debate concerning the governance of the future; in thematic, conceptual, methodological and empirical contexts. My contention in this article, however, is that there is a need to: 1) develop a more sustained and explicit geographical account of the governance of the future than has happened to date; and 2) use a geographical understanding of the governance of the future as part of an effort to promote more socially and spatially just futures. I outline the case for these two arguments in the remaining paragraphs of this section.

First, I maintain that there would be considerable value in developing a more sustained and explicit geographical engagement with the governance of the future. This does not mean that no work has been conducted on such issues. Geographers such as Anderson (2010) and Harvey (2000) have drawn attention, respectively, to some of the key calculative and affective aspects, and some of the important scalar aspects of governing the future. Work beyond Geography - most notably in the history of science - has also examined, in implicit ways, important geographical aspects in the development of Futurology and Futures Studies (e.g. Andersson 2012). And yet, there is room to supplement and extend this work. A number of key themes present themselves as potential avenues of enquiry. There is, evidently, scope to examine some of the important sites, networks and assemblages - or, in other words, "arrangements of humans, materials, technologies, organizations, techniques, procedures, norms, and events" (Baker \& McGuirk 2017, 428) - that have led to the geographical spread of the governance of the future (DeLanda 2016). The historical geographies of Futures Studies has been embedded in specific sites or places, which have become nodes in networks of learning. Key individuals 
and objects include Eric Jantsch writing the report, entitled Technological Forecasting, for the OECD in 1967 in dialogue with the RAND organisation. Important networks and conversations have connected American Futurologists with European forecasters and modellers. Significant events include the Third World Future Research Congress in Bucharest in 1972, which led to the creation of the UNESCOaffiliated World Futures Studies Association (Andersson 2012).

In another context, we need to consider how the governance of the future became enmeshed with geopolitics and the geographies of colonialism. As discussed earlier, conceptualisations of the future, from the outset, were inflected by the realities of the Cold War. At the same time, different inflections of Futurology and Futures Studies were to appear within the west (US vs. European) and the east (Soviet Union vs. satellite states to an extent). The global south too became a playground within which these alternative conceptions of the future could be deployed. The Club of Rome's vision of the future, for instance, reinforced fundamental inequalities between the countries of the north and the south (ibid.). And, as I suggested earlier, there is a real sense in which individual states and nations sought to interpret the study and governance of the future in ways that reflected - at least in part - their own national ideals and priorities. The political geographies of states and nations, thus, had a clear impact on the engagement of scientists with the future. The strong tradition of social democracy and a trust in social science expertise in somewhere like Sweden, for instance, led to a different approach to the study of the future than that adopted in centralist and technocratic France. In Sweden, much more emphasis was placed on developing a democratic and discursive approach to defining alternative futures (Andersson \& Keizer 2014, 108). Such issues also begin to illustrate the significance of geographical scale to the governance of the future. The 1960s and 1970s, arguably, reflected a concern with the governance of global futures. The stance adopted by the Club of Rome, for instance, was that "the world had one common future, and that humanity itself was the central obstacle to that future" (Andersson 2012, 1423). At the other extreme, the local has been emphasised as an appropriate scale over which to imagine more just futures (Saunders \& Jenkins 2012). And of course, sustained attempts have been made to govern the future between these two extremes, with states (Diprose et al. 2008) and regions (Jones et al. 2019) being particularly significant in this respect.

My second claim is that there is a need to develop this more explicitly geographical approach as a way of furthering spatial justice; or, in other words, as a way of developing a version of the future that is more hopeful and just. As I noted in the introduction to this article, the notion of spatial justice is predicated on the idea that space - and, indeed, other kinds of geography - might reinforce inequalities and injustices of different kinds and that it might, conversely, allow new and more effective approaches to inequality and injustice to be imagined. In this respect, it is worth noting that there has been a tendency to date to focus spatial justice within cities and at the urban scale. However, no necessary link exists between spatial justice and the urban scale. Soja (2010, 20; see also Israel \& Frenkel 2017, 4), for example, maintains that "justice and injustice are infused into the multiscalar geographies in which we live, from the intimacies of the household to the uneven development of the global economy". Moreover, adopting Soja's viewpoint encourages to reflect on the different ways in which spatial injustice and justice manifest themselves in different spaces and across different scales. Such an understanding of the interconnection between space, scale and justice also forces us to think carefully about the most appropriate spaces and scales over which spatial justice can be achieved.

The literature on spatial justice, in addition, complements many of the key attributes of Futures Studies. One of the important distinctions between Futurology and Futures Studies, according to Andersson and Keizer (2014) is the technocratic nature of the former and the potential for the latter to be developed on the basis of a more democratic engagement with a wider range of stakeholders. Certainly, the notion of spatial justice tallies well with the more democratic tenor of Futures Studies. Lefebvre (1970), in his study of the right to the city, argued that justice involved the right to take part in urban transformation processes. It was thus associated with an "active participation in the political life, management, and the administration of the city" (Dikeç 2001, 1790). Care needs to be taken, therefore, to ensure that any attempts to govern the future - as a space and time of hope - are as inclusive and democratic as possible. Building on this notion of democratic engagement, emphasis has been placed within the literature on spatial justice on viewing justice, as well as associated terms such as well-being and the 'good life', in plural ways (Sen 1993). It is in this context that Storper (2011, 
19) contends that while "freedom and liberty; the ability to live our lives and be happy; and development of our capabilities" may well be common goals, "different individuals, groups and territories might fill in the detail on these goals in rather different ways". And, in a related context, one needs to consider the extent to which the geographies of the governance of the future - or, in other words, the spaces and scales over which governmental entities operate - allow for a proliferation of understandings of justice and well-being to emerge?

The above discussion illustrates some of the potential ways in which one might be able to highlight the geographies of the governance of the future. Attempts to govern the future appear in different places and come about as result of a movement of people, things and ideas from one location to another (Prince 2016). Likewise, the governance of the future can become embedded in various ways in particular states, nations and regions, and is also played out across a series of connected geographical scales. The above discussion also begins to show some of the significance of such issues for the promotion of more just futures. A more detailed exposition of these ideas, along with their practical limitations, is provided in the next two sections of this article.

\section{Case study and methods}

My case study in this article is Wales and, in particular, its Well-being of Future Generations Act. The choice of case study requires some justification. It is important for the reader to be aware at the outset of this section of the broad changes that have taken place in the governance of Wales in recent years. Wales experienced an executive devolution of power in 1999, with a National Assembly for Wales being created; one that would "give the people of Wales a real chance to express their views and set their own priorities (A Voice for Wales, the UK Government's White Paper on devolution to Wales 1997, 31). Since 1999, Wales has experimented with different forms of governance as a result of a selective process of "filling in" (Jones et al. 2005). It has also been keen to exploit the UK's acceptance of policy divergence (MacKinnon 2015,50) in order to define its own models of policy delivery, whether in relation to education, health and sustainable development. This latter emphasis on sustainable development is particularly significant, as I shall explain below. In all this, we witness Wales' attempts to define a "Welsh way" in relation to public policy delivery (Power 2016) or, as was described by the former First Minister of Wales, to ensure that there was "clear red water" between it and policies in operation across the border in England.

Wales is also a unit of governance that is concerned with the future in many different contexts; ones that reflect the threefold division of the governance of the future I outlined above. To a certain extent, Wales - as is the case with all administrations - seeks to govern risky futures. Some of the most significant contexts for this are in relation to mitigating some of the potential consequences of climate change - with particular attention being directed towards the risk of flooding (Welsh Government 2011) - and the management of the outbreak of a variety of communicable diseases (Public Health Wales 2014). Wales' capacity to govern other future risks is constrained somewhat by the fact that it is a devolved administration that possesses only certain powers; others, such as those relating to justice, are reserved UK powers and responsibilities. The upshot of this situation is that it is the UK's counterterrorism strategy, CONTEST, which is in operation in Wales (Home Department 2018). Taken together, such variation illustrates the complex scalar considerations that inform the governance of risky futures in Wales.

Likewise, the Welsh Government also seeks to predict the future as an aid to governance. One of the most significant developments in this context in recent years has been the creation of a Future Trends unit within the Welsh Government. The logic behind this development is explained as follows:

Forecasting the future is an extremely difficult task. Nevertheless, to make effective decisions now that are good for the long term as well as for our immediate needs, we must use the data we have to attempt to find patterns and trends for the future (Welsh Government 2017, 3).

The most concrete manifestation of the creation of the Future Trends unit is the publication, annually, of a Future Trends report, which seeks to provide useful predictions on trends in relation to varied issues such as population, health, economy and infrastructure, climate change, land use and natural 
resources, and society and culture. The data and projections contained in the report are also useful tools that can enable the Welsh Government to chart its likelihood of reaching some of the challenging goals it has set itself, not least in relation to the Environment (Wales) Act 2016 (where there is a legal target of reducing carbon emissions by a minimum of $80 \%$ by 2050) and the Well-being of Future Generations Act, which, as I shall explain below, possesses a large number of varied targets and goals in relation to well-being, broadly defined (ibid.). Interestingly, too, the Future Trends unit view themselves - and the report they produce - as important stimulators of a "conversation about Wales' future" (ibid., 15). There is a stated attempt here to change what could be a highly technocratic attempt to predict the future into a broader discussion about the possible future trajectories taken by Wales, but evidence concerning the extent of this "conversation" has been limited to date.

This leads me on to the third context within which Wales is seeking to govern the future; namely its attempt to define a future that can express hope and enable justice. It is this third context for the governance of the future that will provide the basis for the empirical section of this article. It is possible to trace Wales' attempt to govern the future in this way to the emphasis that it has placed on sustainable development as a policy goal. Section 121 of the Government of Wales Act 1998, which led to the creation of the National Assembly for Wales, stated clearly that "[the Assembly Government will] make a scheme setting out how it proposes, in the exercise of its functions, to promote sustainable development" (Government of Wales Act 1998, section 121). Wales' pursuit of sustainable development as a policy goal has been viewed, at one level, as something that has allowed it to engage with international audiences, most notably the European Union and the United Nations, in more effective ways (Royles 2010). The Welsh Government's commitment to sustainable development received a further fillip with the promulgation of a Sustainable Development Bill (subsequently the Well-being of Future Generations Act) in 2015. The Act has the ambition that sustainable development will become "the central organising principle" for the public sector in Wales (Nicholl \& Osmond 2012). As part of the Act, a Commissioner for the Well-being of Future Generations has been appointed in order to champion Wales' commitment to sustainable development, well-being and justice, and the Wales Audit Office (the body responsible for auditing the work of public bodies in Wales) has been charged with monitoring the extent to which public bodies are adhering to the aims of the Act. It is this policy context that makes Wales such an appropriate location to study the governance of the future. As well as seeking to govern risky futures and predicting futures, it has - arguably more than many other jurisdictions - placed a great emphasis on attempting to envision more hopeful and just futures.

The empirical material I discuss in this article is drawn from a mixture of three research projects, which have examined Wales' attempt to define and create more hopeful futures. The first project, National Sustainabilities, examined Wales' attempt to define its own interpretation of sustainable development through the concept of well-being and, as such, provides important contextual information for the article. The second project I draw on is an EU Horizon 2020 project, entitled IMAJINE (Integrative Mechanism for Addressing Spatial Justice and Territorial Inequalities, 2017-2021), which brings together 16 partners from 13 European states to discuss and develop new academic and policy understandings of territorial cohesion and spatial justice. Wales is one case study region within this broader network, partly because of its attempt to develop new and imaginative ways of promoting social and spatial justice through the Well-being Act. I also discuss empirical material from a third project. This is a Leverhulme Fellowship, which is examining the way in which behavioural insights are being used in Wales in order to encourage civil servants to think and act in different and more effective ways. An important driver of this change in ways of thinking and doing is the Well-being Act.

The empirical material I discuss from these projects includes approximately 70 interviews conducted in Wales over the course of the past five or so years with a range of civil servants, academics and other stakeholders concerned with sustainable development and the Well-being Act. I was particularly interested here in the hopes associated with the development of the Act, as well as some of the challenges linked to its implementation. I also draw upon documentary research on various strategies, policies and related documents that set out Wales' attempt to define and create a future that is more hopeful and just (for instance, more equitable in terms of life chances and access to services). In terms of analysis, the interview material was transcribed and coded using NVivo using a mixture of codes that were data-generated and others that reflected more conceptual themes (Coffey \& Atkinson 
1996). The documentary material was subject to textual analysis (Kuchartz 2014), where common patterns and similarities within and between documents were noted. I use this interview-based and documentary material in a synthetic manner in the empirical discussion that follows.

\section{Spatial justice and the governance of the future in contemporary Wales}

I proceed in this section to discuss the way in which the Well-being Act has led to a renewed and sustained attempt in Wales to govern the future, and to do so a way of increasing well-being for all of the people of Wales. There is, clearly, an attempt in the Act to focus public and policy attention on the long-term futures of Wales, particularly in relation to its society, economy, culture and environment. The promulgation of the Act was preceded by a large-scale consultation exercise, entitled 'The Wales we Want' (Jones \& Ross 2016). The aims of the exercise were numerous. At one level, it helped to embed sustainable development and the notion of well-being within public discourse in Wales. At another, it encouraged stakeholders of different kinds to envision a future Wales, which would be more sustainable and just. The emphasis on envisioning a 'better' Wales was reinforced by the Welsh Government in its own submission to 'The Wales we Want' exercise. It maintained that

In 2050, Wales will be the best place to live, learn, work and do business...Doing things differently is about looking forward so the choices we take secure a safe and prosperous future for us, for our children and for our grandchildren (Welsh Government 2014, 1).

The level of ambition demonstrated in the above statement is remarkable and it signals - above all else - the radical attempt by the Welsh Government to think proactively about how it might use the Well-being Act to create a different and better kind of Wales.

Particular emphasis was placed in the consultation exercise on asking stakeholders to define the specific vision of sustainable development, well-being and justice that should be striven for by the year 2050. At face value, therefore, there is a clear attempt here to enable multiple visions of the future to be articulated and for these to help define the future of Wales as an object of governance (Rose 1999). The deliberations were said to feed directly into the seven well-being goals that came to structure the Well-being Act. The Act would, by 2050, create: a prosperous Wales; a resilient Wales; a healthier Wales; a more equal Wales; a Wales of cohesive communities; a Wales of vibrant culture and thriving Welsh language; a globally responsible Wales (Welsh Government 2015, 3). While the notion of justice is most clearly associated with the goal of creating "a more equal Wales", it was also linked to some of the other goals. For instance, the issue of a thriving Welsh language has been in recent years been articulated as an issue of linguistic rights (Jones \& Lewis 2019). Similarly, when discussing a prosperous Wales, there is a need, according to the Act, to consider the extent to which such prosperity is shared by the whole of the population of Wales. The idea of justice, therefore, permeates much of the ethos of the Well-being Act.

These seven goals were subdivided into 46 national indicators of progress. While some of these would be well-worn and familiar to policy-makers based in other jurisdictions, such as Gross Value Added (GVA) per hour worked (relative to UK average) (national indicator 9), others were more unusual and reflected the attempt that had been made within the Act to expand understandings of the objectives of government. They included reducing the gender pay difference (national indicator 17), increasing the percentage of people moderately or very satisfied with their jobs (national indicator 20 ), increasing the percentage of people satisfied with their ability to get to/access the facilities and services they need (national indicator 24) and increasing the percentage of people who could speak Welsh (national indicator 37).

There is a sense in the above indicators of the Welsh Government's efforts to envision a more just future for Wales, embedded in notions of well-being and sustainable development. Echoing important aspects of the more conceptual literatures concerning the governance of the future and spatial justice, this is a vision that was based on a democratic process of consultation with the public. Admittedly, the process whereby this public input was distilled into seven well-being goals is relatively opaque, thus posing questions about the extent of consultation exercise: did all voices count and, if so, did they all count equally? What is not in doubt is the way in which the vision of the future encapsulated in the 
Well-being Act extends well beyond GDP or GVA to encompass plural measures of justice and the 'good life'. And as a result, this interpretation of well-being and justice is one that is said to be embedded in key aspects of a Welsh national culture (Jones \& Ross 2016).

In the remaining paragraphs of this section, I want to discuss important geographical - particularly scalar - aspects of the Well-being Act. I focus on three scales, namely the way in which the Act is embedded in a national Welsh scale, its operationalisation at a more local scale within Wales, and its implications for more embodied ways of working. Of course, while I examine each of these scales of governance in isolation, I fully recognise the important connections that exist between them (cf. Swyngedouw 2000). In discussing these significant geographies of the Well-being Act, my other goal is to reflect on the impact of these distinct geographies on the Welsh Government's stated aims of achieving well-being and justice. It is in this second context that one can begin to appreciate the extent to which the governance of the future - as reflected in the Well-being Act - is helping or hindering the Welsh Government to achieve spatial justice.

\section{Scaling future governance 1: the national scale}

The discussion in the above paragraphs points, quite clearly I maintain, to the way in which the Wellbeing Act reflects an attempt to ground notions of well-being, sustainable development and justice at the scale of Wales as a devolved state, region and/or nation. We can identify the attempts to embed understandings of justice at a Welsh national scale in many distinct, yet related, contexts. First, it is clear that ever since the beginning of the devolution process there has been an attempt discursively to construct well-being and justice as issues and goals for Wales as a nation. One of the most clear-cut examples of this emphasis was the naming of 'The Wales we Want' exercise, described earlier. Evidently, the common-sense geographical frame of reference for sustainable development and wellbeing in this case is Wales (Jones \& Ross 2016). Some of the Welsh Government's statements about the significance of sustainable development and well-being - both prior to and following 'The Wales we Want' consultation - reinforce this geographical connection with Wales as a nation. The ministerial foreword to the Welsh Government's Sustainable Development Scheme, One Wales: One Planet, for instance, states that "I hope that you will be able to support and join us in this endeavour [the journey to sustainability], so that together we can transform Wales into a sustainable nation" (Welsh Government 2009, 5). Even more strident comments were made in the later Sustainable Development Report published by the Welsh Government. Here, it is confidently stated that Wales has "its own account of sustainable development", with an "emphasis on social, economic and environmental wellbeing for people and communities, embodying our values of fairness and social justice" (Welsh Government 2012, 5). A form of banal nationalism (Billig 1995) - or, in other words, a nationalism that is reproduced in subtle and highly banal contexts - is evident in all of these statements, with the use of plural pronouns such as 'us', 'we' and 'our' helping to emphasise that Wales as a nation is taking possession of a distinctive approach to sustainable development, well-being and justice.

An even more explicit and instrumental attempt discursively to connect sustainable development and well-being to Wales, a Welsh nation and the Welsh national scale appears in the Sustainable Development Narratives for Wales document, which was published in November 2013. The document used behavioural insights in order to highlight the specific discourses - in terms of language, idioms and imagery - that could be used to 'sell' the idea of sustainable development to a Welsh nation (Welsh Government 2013). The guide drew on ideas from social marketing (Pykett et al. 2014), in which marketing insights from the private sector are used in order to promote public goals, to target specific segments of the population with bespoke messages. As noted by Sustain Wales, the NGO that was responsible for producing the document, the art of social marketing "requires an understanding of specific groups of people - what they value, what they identify with, who they are - and the language that resonates with them" (Sustain Wales 2012,1). The key point I want to make at this juncture is that the Welsh nation was viewed in these documents as a significant segment for the promotion of sustainable development and that there was, thus, a need to create a bespoke take on sustainable development that would resonate with the Welsh nation. 
Second, the evidence points to an emphasis being placed on Wales as a focus for intervention as a result of the national challenges that it has faced and continues to face. This theme was especially apparent in some of the interviews I conducted with workers in Sustain Wales, the NGO responsible for 'The Wales we Want' consultation. One reflected on how the problematic history of Wales should act as a spur for Wales to create a new and better Wales of the future, as the following quote illustrates:

Wales was there at the start of the industrial revolution and the production of coal and then the export right across the world...So it's benefited from it but it's also been, pardon the pun, at the coalface of it. So it's seen its landscapes absolutely scarred, it's got the communities that are now being hit by inertia (Interview, Sustain Wales).

The same individual described how the challenges facing Wales in the present should be viewed as sources of inspiration for future action; once again at the scale of Wales as a region and nation. The respondent explained that "Wales has some of the highest rates of obesity in the world, some of the highest rates of teenage pregnancy". They viewed these statistics as ones that needed to change as Wales moved forward (Interview, Sustain Wales).

This kind of attitude - about the need to get to grips with some of the entrenched challenges facing Wales as a nation - has translated into the priorities that have been set by Sophie Howe, the Commissioner for the Well-being of Future Generations. In her first Annual Report, she identified two main areas of intervention. The first emphasised the need to create "the right infrastructure for future generations", including improving the housing stock, energy generation and efficiency as well as transport planning (OFGC 2018, 21). The second centred on "[e]quipping people for the future", with a focus on improving skills for the future, addressing adverse childhood experiences (ACEs) and promoting alternative models for improving health and well-being (ibid.). There is a certain logic to the approach that has been adopted by the Commissioner. At one level, these are patently fundamental challenges facing Wales as a nation and a region. At the same time, it is impossible for the Office of the Commissioner to give equal attention to each of the seven well-being goals contained in the Wellbeing Act. And yet, there are important questions that are deserving our attention. To what extent, for instance, are these challenges and priorities equally relevant to all people and all parts of Wales? Wales, after all, is varied in terms of its social, economic, cultural and environmental makeup. There is room to suggest, in this respect, that the priorities emphasised by the Commissioner during her first years in office reflect well-being challenges that are significant for the more urbanised areas of southeast Wales, with challenges associated with the more rural areas of Wales - isolation, access to services and the Welsh language for instance - being marginalised as a result (cf. Luukkonen \& Sirviö forthcoming). As such, there is a danger that emphasising a set of national priorities in relation to wellbeing and justice will, inadvertently perhaps, lead to an implicit focusing of attention, services and funding on certain areas more than others. In effect, one could have a situation in which attempts to address injustice could exacerbate spatial injustice by prioritising certain areas more than others. To what extent, therefore, can just futures be defined at a national or regional scale? Such concerns point to the potential value in developing a more localised interpretation of well-being and justice, and I turn to this theme in the next sub-section.

\section{Scaling future governance 2: operationalising well-being and justice at the local scale}

Another significant aspect of the Well-being Act is the way in which it has attempted to ground understandings of well-being in localities. The Act has led to the creation of a series of Public Services Boards (hereafter PSBs) and, with a few small exceptions, these have been centred on local authority areas. The PSBs consist of the relevant local authority and representatives from the Local Health Board, the Welsh Fire and Rescue Authority, Natural Resources Wales (the body responsible for managing the environment of Wales), the relevant Chief Constable, the relevant Police and Crime Commissioner, and a representation from local voluntary bodies (Welsh Government 2015, 11). PSBs are responsible, furthermore, for consulting with the local population in order to produce assessments of local well-being, encompassing economic, social, environmental and cultural themes. These assessments are then used to develop local well-being plans, which contain "objectives that are designed to maximise the PSB's contribution to locally-defined well-being goals" (ibid.). 
At face value, PSBs provide a welcome antidote to the potential homogenising tendencies of the Well-being Act at the national scale. The first iterations of the local well-being assessments and plans have now been produced. There are references in some of these documents to the issues that have been identified as national priority areas by the Commissioner for Well-being. For instance, PSBs in diverse locations in Wales - Torfaen and Blaenau Gwent in post-industrial South Wales, and Ceredigion, and Gwynedd and Anglesey in more rural West Wales - all reference in slightly different ways to the need to address adverse childhood experiences. And yet, at the same time, there are efforts in these documents to emphasise more localised and distinctive aspects of justice and well-being. Torfaen PSB (2017) for instance, draws attention to the need to prevent chronic health conditions and to improve local skills, Blaenau Gwent PSB (2017) makes a case for increasing healthy lifestyle chocies, Ceredigion PSB (2017) notes the need for individual well-being within communities, and Gwynedd and Anglesey PSB (2017) emphasises the need to protect and promote the Welsh language, as well as the need to understand demographic changes and ensure that there is a sufficient stock of affordable housing (the latter two priorities are, once again, linked to local debates about the in-migration of English speakers to the area and the lack of availability of affordable housing for Welsh-speaking residents).

This variation could be viewed as a testament to an attempt to localise well-being, with spatial justice in this sense being more effective and far-reaching if it is defined through a democratic process of engagement taking place at the local scale. And yet, certain concerns can be raised about the effectiveness of this process. While these reflect practical and operational difficulties, at one level, they also testify to more fundamental and conceptual challenges associated with defining well-being and spatial justice at the local scale. First, concerns have been raised about the extent to which PSBs have considered fully the spatial aspects of well-being in the production of their local well-being assessments and plans. In a publicly released review report, the Commissioner for Future Generations commented that:

The assessments acknowledge the importance of local spaces as assets, acknowledge their roles in people's well-being and consider how people engage and interact with these places. However, most well-being assessments showed very limited consideration of the significance or cause of spatial differences, including: life expectancy; the distribution and isolation of elderly residents; the differences between rural and urban or inland and coastal communities; biodiversity loss; community safety or the impact of climate change. These were described as relevant problems, but their localised impact on well-being remained unexplored (OFGC 2017,15).

The collective feedback provided above by the Future Generations Commissioner to PSBs is significant. It encourages PSBs, I contend, to think in more creative ways about the significance of space to wellbeing. And it is interesting that this is a spatial perspective that should feed into a range of aspects of social life.

Second, some within the voluntary sector have bemoaned that their potential to provide input into the work of the PSBs, as well as the production of well-being assessments and plans, is limited. Echoing familiar and long-running criticisms levelled at the idea of partnership working, it has been suggested that PSBs are dominated by the public sector, with concomitant worries about the unevenness of power relationships, which are redolent of forms of metagovernance (Jessop 2016) or a 'shadow state' (Wolch 1990). Clearly, there are implications here for spatial justice, particularly in relation to the (in) ability of those working within the voluntary sector in different parts of Wales to contribute fully to the definition of future goals.

Third, it is also possible to question how the subsidiarity associated with the Well-being Act - as embodied in the notion of PSBs, local well-being assessments and plans - is actually serving to undermine some of the Act's essential characteristics; and, by extension, the notion of spatial justice. The significance of this issue can be seen most clearly in relation to the Act's commitment to the Welsh language as an important aspect of 'The Wales we Want'. A well-placed individual working in Sustain Wales, the body responsible for promoting sustainable development in Wales prior to the passing of the Well-being Act, explained some of the reasoning behind this emphasis on promoting the Welsh language:

The kind of Wales we would like to see would be in terms of equality, in all things...The language would be key...We're the only place in the UK trying to develop bilingualism and that is something 
we need to be really proud of to show as a nation we're proud of our heritage and culture (emphasis added).

As well as demonstrating the distinctiveness of Wales' interpretation of sustainable development and well-being, the above statement clearly indicates a commitment to the Welsh language as something that is significant for the whole of the Welsh nation. And yet, the brief description of the priorities of four PSBs, provided earlier, demonstrates quite clearly an uneven commitment to the Welsh language. It is only in Gwynedd and Anglesey PSB (2017) that there is any overt statement about the significance of the Welsh language for understandings of well-being. Ceredigion PSB $(2017,7)$ has seen fit to incorporate certain goals that might have some tangential benefits for the Welsh language within their local well-being plans. The place of the Welsh language within local well-being plans is even more muted, though, when one studies those PSBs located in parts of Wales possessing lower percentages (though sometimes large absolute numbers) of Welsh speakers; places such as Torfaen and Blaenau Gwent. As such, the local well-being assessments and plans that have been produced - and the institutional priorities that they reflect - are, I contend, in danger of reproducing familiar geographies of the Welsh language; with the Welsh language being viewed as a legitimate well-being goal for those areas of Wales possessing higher percentages of Welsh speakers while being deemed as an irrelevance for PSBs operating in parts of Wales possessing lower percentages of Welsh speakers (Jones \& Lewis 2019). What are the impacts of such variations on the linguistic aspects of spatial justice? Will Local Well-being Plans help to determine access to Welsh-medium services in the future and, if so, will it lead to a situation in which the institutional support provided for the Welsh language - and for Welsh speakers - can legitimately vary from one part of Wales to another? There is clearly, here, the potential for the devolved character of the Well-being Act to lead to a situation in which the Welsh language faces additional challenges in certain parts of Wales, rather than being supported as one of the Act's seven well-being goals.

Of course, I can be accused, in this respect, of wanting to have my cake and eat it. In the previous section, I argued that there was a need to be wary of the homogenising tendencies that might be associated with approaching the idea of well-being and spatial justice at the national scale. In this section, I am suggesting that we need to be careful that embedding well-being and spatial justice within localities does not lead to a situation in which access to opportunities and services vary spatially. My defence is that in pursuing these - perhaps conflicting - arguments we witness the challenges associated with seeking to promote well-being and justice. Moreover, I seek to demonstrate that the geographies and, particularly in this case, the scales over which this endeavour is operationalised possess consequences for the justice that can be achieved.

\section{Scaling future governance 3: the body and mind as terrains of governance}

The third and final scale of future governance I want to discuss relates to the body and mind as key terrains of governance. One of the most significant aspects of the Well-being Act is the emphasis that it has placed on encouraging five new ways of working, highlighting the need to: think about the long term; prevent problems occurring or getting worse; integrate different well-being objectives and the work of different public bodies; collaborate with any stakeholder that might help a well-being goal to be achieved; involve any individuals and groups who might have an interest in a well-being goal (Welsh Government 2015, 7). The most significant of these for the present discussion, of course, is the first and it is worth considering the specific wording of this new way of working. It is stated that thinking about the long term reflects "[t]he importance of balancing short-term needs with the needs to safeguard the ability to also meet long-term needs" (ibid.). As such, this different way of working reflects both the overall tenor of the Well-being Act, namely that there is a need to create a new, different and better kind of Wales by the year 2050. It is also a new way of working, at least in an implicit sense, that is borne out of a concern with the short-termism of politics and policy-making in general. As one respondent from the Welsh Government put it, "part of the problem we have is that civil servants aren't used to thinking over the long term. They get tied in to the electoral cycle, which emphasizes the need for short-term gain" (interview, Welsh Government). 
Such concerns have resulted in a concerted effort to retrain civil servants, particularly within the Welsh Government, so that they are better suited to taking on board the requirements of the Act. A number of bodies in Wales have taken up this challenge. The Wales Audit Office, for instance, has created a Good Practice Exchange in order to help civil servants to think and act differently in relation to the Well-being Act (and also with regard to the relatively new Social Services and Well-being Act, and the Environment Act). An example of their work includes a recent training course on encouraging public sector workers to take more seriously the outcomes of their work, rather than the current focus on measuring outputs. As Jeffs (2018), one of the contributors to the training course, states "the true 'value' of public service ultimately lies in improving people's lives" and, as such, there needs to be a concomitant "different way of seeing and providing public services that starts with people's lives and what matters to them in their lives". While this is a laudable goal in its own right, I also suggest that it also reflects - and least implicitly - an attempt to move away from the short-termism of an outputfocused approach to one that takes heed of the longer-term consequences of policy delivery. Similar work is undertaken by Academi Wales, which is linked to the Welsh Government's Cabinet Secretary for Local Government and Public Services. The aim of Academi Wales is to be the centre for excellence in leadership and management for public services in Wales, and one of the values it seeks to instil among civil servants is to "work for the long term" (https://academiwales.gov.wales, accessed 10.1.2019).

While this is, evidently, a laudable goal and one that tallies with the overall tenor of the Well-being Act, it seems as if it is much easier to say than it has been to achieve. An analysis of some of the courses and guidance provided by Academi Wales, for instance, shows that they are aware of the need to address long-term futures but the guidance provided is a little vague. Its discussion of a Sustainable Futures Development Architecture starts with the need to think over the long term and the need to move away from so-called "short term fixes" but the solution to this issue, seemingly, focuses far more on collaboration and involvement ways of thinking:

Long term relationships. To solve tough problems, we need everyone who is prepared to help; the recipient or customer has just as much to bring as the field expert. We commit to people to help discover and build on all our strengths and create relationships that increase trust (Academi Wales 2015, 1).

Again, there is much to commend in the above statement but it does not, as far as I can see, get to grips with the need to think about the long term. The development of strong collaborative links and trust between policy-makers and the public may be a part of achieving this goal but where is a consideration here of the long-term consequences of policy decisions in the present? How does the above guidance help policy-makers to think creatively about how small-scale decisions and investments in the present might have large-scale positive outcomes in the future, or how one needs to think carefully about the unintended long-term consequences of decisions in the present for ideas of wellbeing and justice?

Some of the interventions that have been run out of the Department of Geography and Earth Sciences at Aberystwyth University have attempted to exploit understandings of behavioural insights (Jones et al. 2013) and mindfulness as a way of addressing some of the short-comings of policy-makers and policy-making, including the lack of long-term thinking (Kahneman 2011; Academi Wales 2018, 5). One intervention was developed in order to explore whether the experience of practising mindfulness would enable participants to enhance their understanding of the principles that inform contemporary behaviour change policies. Fifteen civil servants in the Welsh Government were trained over the course of eight weeks to reflect on their behaviours and those of the stakeholders that they interact with. While those who attended the course identified many positive aspects (see Lilley et al. 2014), some of the more interesting themes arose in relation to the perceived increased capacity of attendees to manage their time, to think more slowly and to reflect on the longer-term consequences of their decision-making, as the following quote shows:

I think that it's really important having the capacity to learn and think rather than just going with the prevailing wind [...] if you do that you can start changing how you see, even how you look, at things. If you don't give yourself space I think that you just get caught-up with the tide (civil servant, Welsh Government). 
Again, while it may not be possible to equate being "caught up with the tide" with a short-term attitudes towards policy-making, one can see how there is some potential here for the training course to encourage civil servants to avoid making knee-jerk policy decisions; ones that are more likely to be short term in their outlook.

The discussion in this sub-section illustrates how the Well-being Act is leading to an effort on behalf of various organisations to encourage public servants to think about the long term impact of their decisions and policies. There is, moreover, some evidence to show that behavioural insights are being used as a way of encouraging this different way of working. While these insights seek to help civil servants to reframe their policy decisions in different ways (reflecting the five different ways of working encompassed by the Act), there is some doubt as to the extent to which they are successful means of allowing civil servants to make policy decisions that fully take account of the specific need to create a long-term perspective on policy-making. Such concerns point to the need for more research on the practical implications of seeking to govern of the long term.

\section{Conclusions}

My aims in this article were twofold. I discussed the growing interest in the governance of the future within academia and argued that there was a need to develop a more explicit and sustained engagement with the geographical aspects of this process. I also maintained that developing such a geographical perspective was necessary as a way of ensuring that attempts to govern the future were as spatially just as possible. Geography, in this sense, is not merely a backdrop to efforts to promote justice and well-being. It has a significant bearing on the extent to which justice and well-being can be achieved. I illustrated these conceptual claims with a discussion of the development and implementation of the Well-being Act in Wales; an Act that explicitly seeks to create a different and better kind of Wales by the year 2050 .

The Act promotes a notion of well-being and justice at different scales and each of these possess implications for the way in which well-being and justice can be achieved in practice. The Act's discursive emphasis on the national scale - while being something that can make the notion of sustainable development, well-being and justice something that is embedded in Welsh values (Jones \& Ross 2016) - can lead to a situation in which certain issues are prioritized above others; with a potential for unjust outcomes to emerge. The Act's emphasis on the local scale - particularly in relation to the work of PSBs - also has the potential to lead to situations in which some of the Act's overall aims are downplayed or ignored. Once again, certain interest groups and particular areas may suffer as a result. And the Act's emphasis on the body and minds of civil servants as terrains of governance is also significant. Yet, there is still some doubt as to the extent to which the training and interventions that have been trialed to date have been wholly effective in reshaping values and sensibilities; particularly in relation to the need to think and act in ways that promote long-term goals. And even though it was not discussed in the main body of the article, there is some tentative evidence to show that the Wellbeing Act is having some impact internationally. The Well-being Commissioner presents regularly to international audiences about Wales' experiment with governing the future and there is a sense that the Act has already served to raise Wales' profile internationally.

The overall message that comes out of this case study is that whereas there is an appetite for governing the future, and to do so as a means of furthering sustainable development, well-being and justice, the act of operationalising this - at least in relation to geographical themes - is fraught with difficulty. There are no simple means of addressing such challenges. Rather than providing simple answers, for now it may enough for geographers - because of their sensitivity to the difference that geographical issues, such as space and scale make, to politics and governance - to take the lead in drawing attention to the significance of the questions that need to be asked when seeking to govern the future. How do the spaces and scales over which more hopeful futures are being articulated influence the extent to which those hopeful futures can be realised? To what extent do these spaces and scales of future governance lead to greater justice for some rather than others? In short, how does this search for future justice play out in spatial contexts? 
And if these kinds of questions are pertinent within the specific context of Wales, they are even more significant when one considers spatial justice at broader geographical scales. If one key aspect of spatial justice is that individuals, groups, cities, regions and states can articulate their own vision of what a just future might look like (Storper 2011, 19), then surely they must be allowed the same license to define the spaces and scales over which that search for justice occurs. In short, the spaces and scales of future governance might vary from one place to another; some spaces and scales of future governance might work more effectively in some places than others. There is a need, therefore, for a spatial sensitivity to spatial justice and geographers should play a leading role, not just in analysing this spatial variation, but also in enabling the most effective governmental configurations to be developed within specific geographical settings.

\section{Notes}

${ }^{1}$ While I refer to attempts to govern the future in this article, it will become apparent throughout that I do not consider the future as something that is singular and predetermined. There are, therefore, many possible futures that might be problematized and imagined as objects of governance (Rose 1999; Dikeç 2007). Therefore, while I use the term 'governing the future', the reader should be aware of the many possible interpretations of the future that underlie its use.

\section{Acknowledgements}

I am grateful to the audience at the Geography Days conference for their comments on the oral version of this paper, and for the two referees for their useful and insightful comments on the written version. I would also like to thank Bryonny Goodwin-Hawkins for conducting the interviews for the IMAJINE project. I also would like to acknowledge the financial support of the following organisations: the AHRC for the project on National Sustainabilities (grant number AH/K004077/1); the European Commission for the IMAJINE project (grant number REP-726950-1); the Leverhulme Trust for the project on the use of behavioural insights by the Welsh Government (grant number RF-2017-696). All the errors and omissions are mine.

\section{References}

Academi Wales (2015) Sustainable Futures Development Architecture. Academic Wales, Cardiff.

Academi Wales (2018) Decision Making: Deliberately Disciplined Leaders Make Better Choices. Academi Wales, Cardiff.

Anderson, B. (2010) Preemption, precaution, preparedness: anticipatory action and future geographies. Progress in Human Geography 34(6) 777-798. https://doi. org/10.1177/0309132510362600

Andersson, J. (2006) Choosing futures: Alva Myrdal and the construction of Swedish Futures Studies, 1967-1972. International Review of Social History 51(2) 277-295. https://doi.org/10.1017/ S0020859006002458

Andersson, J. (2012) The Great Future Debate and the struggle for the world. American Historical Review 117(5) 1411-1430. https://doi.org/10.1093/ahr/117.5.1411

Andersson, J. \& Keizer, A-G. (2014) Governing the future: science, policy and public participation in the construction of the long term in the Netherlands and Sweden. History and Technology 30(1-2) 104-122. https://doi.org/10.1080/07341512.2014.932563

Baker, T. \& McGuirk, P. (2017) Assemblage thinking as methodology: commitments and practices for critical policy research. Territory, Politics, Governance 5(4) 425-442. https://doi.org/10.1080/21622 $\underline{671.2016 .1231631}$

Beck, U. (1992) The Risk Society: Towards a New Modernity. Sage, London.

Billig, M. (1995) Banal Nationalism. Sage, London.

Blaenau Gwent PSB (2017) Blaenau Gwent Draft Well-being Plan. Blaenau Gwent Public Services Board, Ebbw Vale.

Boykoff, M. (2008) The cultural politics of climate change discourse in UK tabloids. Political Geography 27(5) 549-569. https://doi.org/10.1016/j.polgeo.2008.05.002 
Ceredigion PSB (2017) Ceredigion Draft Well-being Plan. Ceredigion Public Services Board, Aberaeron. Coffey, A. \& Atkinson, P. (1996) Making Sense of Qualitative Data: Complementary Research Strategies. Sage, London.

Dabinett, G. (2011) Promoting territorial cohesion and understandings of spatial justice. Paper for the DG Regio, Regional Studies and Slovenia Government Office for Local Self-Government and Regional Policy Conference: What future for Cohesion Policy? An academic and policy debate. Sava Hoteli Bled, Slovenia, 16-18 March 2011.

DeLanda, M. (2016) Assemblage Theory. Edinburgh University Press, Edinburgh.

Dikeç, M. (2001) Justice and the spatial imagination. Environment and Planning A 33(10) 1785-1805. https://doi.org/10.1068/a3467

Dikeç, M. (2007) Space, governmentality, and the geographies of French urban policy. European Urban and Regional Studies 14(4) 277-289. https://doi.org/10.1177/0969776407081162

Diprose, R., Stephenson, N., Mills, C., Race, K. \& Hawkins, G. (2008) Governing the future: the paradigm of prudence in political technologies of risk management. Security Dialogue 39(2-3) 267-288. https://doi.org/10.1177/0967010608088778

Government of Wales Act (1998) Government of Wales Act (1998). HMSO, London.

Gwynedd and Anglesey PSB (2017) Gwynedd and Môn Draft Well-being Plan. Gwynedd and Môn Public Services Board, Caernarfon and Llangefni.

Harvey, D. (2000) Spaces of Hope. University of California Press, Berkeley, CA.

Hinchcliffe, S. \& Bingham, N. (2008) Securing life: the emerging practices of biosecurity. Environment and Planning A 40(7) 1534-1551. https://doi.org/10.1068/a4054

Home Department (2018) CONTEST: The United Kingdom's Strategy for Countering Terrorism. UK Home Department, London.

Hulme, M. (2008) The conquering of climate: discourses of fear and their dissolution. The Geographical Journal 174(1) 5-16. https://doi.org/10.1111/j.1475-4959.2008.00266.x

Israel, E. \& Frenkel, A. (2017) Social justice and spatial inequality: toward a conceptual framework. Progress in Human Geography 42(5) 647-665. https://doi.org/10.1177/0309132517702969

Jeffs, M. (2018) Moving from outputs to outcomes. <https://goodpracticeexchange.wales/2018/05/15/ moving-from-outputs-to-outcomes/>

Jessop, B. (2016) Territory, politics, governance and multispatial metagovernance. Territory, Politics, Governance 4(1) 8-32. https://doi.org/10.1080/21622671.2015.1123173

Jones, R., Goodwin, M., Jones, M. \& Pett, K. (2005) “Filling in" the state: economic governance and the evolution of devolution in Wales. Environment and Planning C: Government and Policy 23(3) 337360. https://doi.org/10.1068/c39m

Jones, R., Pykett, J. \& Whitehead, M. (2013) Behaviour change policies and psychological governance. Policy and Politics 41(2) 159-182. https://doi.org/10.1332/030557312X655422

Jones, R. \& Ross, A. (2016) National sustainabilities. Political Geography 51 53-62. https://doi. org/10.1016/j.polgeo.2015.12.002

Jones, R. \& Lewis, H. (2019) New Geographies of Language: Language, Culture and Politics in Wales. Palgrave Macmillan, London. https://doi.org/10.1057/978-1-137-42611-6

Jones, R., Moisio, S., Weckroth, M., Woods, M., Luukkonen, J., Meyer, F. \& Miggelbrink, J. (2019) Reconceptualising territorial cohesion through the prism of spatial justice: critical perspectives on academic and policy discourses. In Lang, T. \& Görmar, F. (eds.) Regional and Local Development in Times of Polarisation: Re-thinking Space Politics in Europe, 97-120. Palgrave Macmillan, London. https://doi.org/10.1007/978-981-13-1190-1 5

Kahneman, D. (2011) Thinking, Fast and Slow. Farrar, Straus and Giroux, New York, NY.

Kuchartz, U. (2014) Qualitative Text Analysis: A Guide to Methods, Practice and Using Software. Sage, London. https://doi.org/10.4135/9781446288719

Lefebvre, H. (1970) La Révolution Urbaine. Gallimard, Paris.

Lilley, R., Whitehead, M., Howell, R., Jones, R. \& Pykett, J. (2014) Mindfulness, Behaviour Change, and Engagement in Public Policy: An Evaluation. Aberystwyth University.

Luukkonen, J. \& Sirviö, H. (forthcoming) Politics of depoliticization and the constitution of cityregionalism as a dominant spatial-political imaginary in Finland.

MacKinnon, D. (2015) Devolution, state restructuring and policy divergence in the UK. The Geographical Journal 181(1) 47-56. https://doi.org/10.1111/geoj.12057

Massumi, B. (2007) Potential politics and the primacy of pre-emption. Theory and Event 10(2) Project MUSE. https://doi.org/10.1353/tae.2007.0066

Mouffe, C. (2013) Agonistics: Thinking the World Politically. Verso, London. 
Nicholl, A. \& Osmond, J. (2012) (eds.) Wales' Central Organising Principle. Institute of Welsh Affairs and Sustain Wales, Cardiff.

OFGC (2017) Well-being in Wales: Planning Today for a Better Tomorrow. Learning from Well-being Assessments 2017. Office of the Future Generations Commissioner, Cardiff.

OFGC (2018) Future Generations Commissioner for Wales: Annual Report 2017-2018. Office of the Future Generations Commissioner, Cardiff.

Power, S. (2016) The politics of education and the misrecognition of Wales. Oxford Review of Education 42(3) 285-298. https://doi.org/10.1080/03054985.2016.1184871

Prince, R. (2016) The spaces in between: mobile policy and the topographies and topologies of the technocracy. Environment and Planning D: Society and Space 34(3) 420-437. https://doi. org/10.1177/0263775815618401

Public Health Wales (2014) The Communicable Disease Outbreak Plan for Wales. Public Health Wales, Cardiff.

Pykett, J., Jones, R., Welsh, M. \& Whitehead, M. (2014) The art of choosing and the politics of social marketing. Policy Studies 35(2) 97-114. https://doi.org/10.1080/01442872.2013.875141

Rose, N. (1999) Powers of Freedom: Reframing Political Thought. Cambridge University Press, Cambridge. https://doi.org/10.1017/CBO9780511488856

Royles, E. (2010) Small, smart, successful: a nation influencing the twenty-first-century world? The emerging Welsh paradiplomacy. Contemporary Wales 23 142-170.

Saunders, A. \& Jenkins (2012) 'Absent fear': re-envisioning a future geography. Futures 44(5) 494503. https://doi.org/10.1016/j.futures.2012.02.002

Sen, A. (1993) Capability and well-being. In Sen, A. \& Nussbaum, M. (eds.) The Quality of Life, 30-53. Clarendon Press, Oxford. https://doi.org/10.1093/0198287976.003.0003

Soja, E. (2010) Seeking Spatial Justice. University of Minnesota Press, Minneapolis, MN. https://doi. org/10.5749/minnesota/9780816666676.001.0001

Storper, M. (2011) Justice, efficiency and economic geography: should places help one another to develop?EuropeanUrbanandRegionalStudies 18(1)3-21.https://doi.org/10.1177/0969776410394553

Sustain Wales (2012) Narratives for a Sustainable Wales: Values, Language and Identity. Sustain Wales, Cardiff.

Swyngedouw, E. (2000) Authoritarian governance, power, and the politics of rescaling. Environment and Planning D: Society and Space 18(1) 63-76. https://doi.org/10.1068/d9s

Torfaen PSB (2017) Torfaen Draft Well-being Plan. Torfaen Public Services Board, Pontypool.

Welsh Government (2009) One Wales: One Planet. The Sustainable Development Scheme of the Welsh Assembly Government. Welsh Government, Cardiff.

Welsh Government (2011) National Strategy for Flood and Coastal Erosion Risk Management in Wales. Welsh Government, Cardiff.

Welsh Government (2012) Sustainable Development Annual Report of 2011-2012. Welsh Government, Cardiff.

Welsh Government (2013) Sustainable Development Narratives for Wales: A Framework for Communications. Welsh Government, Cardiff.

Welsh Government (2014) Written Statement - The Future Generations Bill. The Wales we Want by 2050. Welsh Government, Cardiff. <https://gov.wales/about/cabinet/cabinetstatements/previousadministration/2014/futuregenerationsbill/?lang=en>

Welsh Government (2015) Well-being of Future Generations Act: The Essentials. Welsh Government, Cardiff.

Welsh Government (2017) Future Trends Report 2017. Welsh Government, Cardiff.

Wolch, J. (1990) The Shadow State: Government and Voluntary Sector in Transition. Foundation Center, New York, NY. 